\title{
Sub-Epithelial Connective Tissue Graft to Increase the Volume of Residual Alveolar Bone in the Upper Anterior Sector and Fixed Rehabilitation with Zirconia
}

\author{
Minor Enrique Zuñiga Araya,,2, Rita Elizabeth Martínez Martínez ${ }^{1,2}$, \\ José Honorio Olvera Delgado, ${ }^{1,2}$, Jaime Alejandro Nieto Ramirez ${ }^{1,2}$, \\ Elena A. Popoca Hernandez ${ }^{1,2}$, José Luis Ayala Herrera ${ }^{1,2 *}$ \\ ${ }^{1}$ San Luis Potosi University, San Luis Potosi, Mexico \\ ${ }^{2}$ Universidad Autónoma de San Luis Potosí, San Luis Potosí, México \\ Email:^dr.ayala02@gmail.com
}

How to cite this paper: Zuñiga Araya, M.E., Martínez Martínez, R.E., Olvera Delgado, J.H., Nieto Ramirez, J.A., Popoca Hernandez, E.A. and Ayala Herrera, J.L. (2018) Sub-Epithelial Connective Tissue Graft to Increase the Volume of Residual Alveolar Bone in the Upper Anterior Sector and Fixed Rehabilitation with Zirconia. Open Journal of Stomatology, 8, 189-195. https://doi.org/10.4236/ojst.2018.86018

Received: March 3, 2018

Accepted: June 12, 2018

Published: June 15, 2018

Copyright ( $\odot 2018$ by authors and Scientific Research Publishing Inc. This work is licensed under the Creative Commons Attribution International License (CC BY 4.0).

http://creativecommons.org/licenses/by/4.0/

\begin{abstract}
Background: The collapse of the alveolar ridge in an edentulous area in patients who will undergo oral rehabilitation impedes the harmonic relationship between pontic and ridge. To correct this type of defect there are several surgical techniques that aim to achieve soft tissue augmentation, allowing the conformation of an ideal profile with the use of a pontic. The aim was to demonstrate how the technique of tissue modification in an area with a class $b$ defect of Allen allows the correction of aesthetics in the anterior dental sector. Case presentation: A 41-year-old Mexican woman. Extra and intraoral examination was performed, the dental treatment included connective tissue graft and rehabilitation with Zirconia. Conclusion: Surgery of residual alveolar ridge augmentation with connective tissue graft gives the patient favorable aesthetic results in the anterior area when it will be rehabilitated.
\end{abstract}

\section{Keywords}

Esthetic Zone, Zirconia, Class B Defect of Allen

\section{Introduction}

In aesthetic and restorative dentistry, before performing any treatment when the main objective is to correct an aesthetic defect or keratinized gingiva, the tissue volume required to eliminate the deformity of the alveolar ridge must be ana- 
lyzed, achieving a harmony between the tissues and the rehabilitation. Therefore, different surgical graft techniques should be considered. Protocols should be established for the procedures to be carried out [1] and the design of the provisional and the definitive restoration should be planned [2] [3]. Reconstructive plastic surgery allows the hard and soft tissues of the alveolar ridge to be restored to their previous dimensions and gives the restorative dentist the opportunity to provide patients with fixed prostheses that are truly aesthetic and that will improve Dentofacial harmony [2]. In the literature, they have been presented with several surgical modifications for the increase of the localized ridge. It consists of three basic approaches: Placement of a gross and free mucosal autograft, type "onlay" in the defect of the ridge, placement of an autograft of fibrous connective tissue sub epithelial at the site of the defect and placement of sub periosteal hydroxyapatite in the deformity [4].

Allen classifies residual alveolar ridge defects in: Class A: A loss of the apical-coronal dimension; Class B: A loss of the buccolingual dimension; Class C: A loss of the apical-coronal and buccolingual dimension. It also introduces the concept of severity, assessing defects of less than $3 \mathrm{~mm}$ as mild, 3 to $6 \mathrm{~mm}$ as moderate and those greater than $6 \mathrm{~mm}$ as severe [5]. The sub-epithelial connective tissue grafts reported by Langer and Calagna in 1980 and Gaber and Rosenberg in 1981 have greatly helped to completely reconstruct class B defects [6]. The ideal techniques for the increase of the alveolar ridge, are the free grafts in the tunnel, interposed or inlay and superimposed or onlay. In tunnel graft procedures [5] [7], a sub-epithelial envelope is created in the area of the ridge deformity. This preparation could be developed with three different incision techniques; First, the technique consists of a coronary incision made by palatal or lingual defect, called coronal-apical; a second technique that is based on a horizontal incision near the mucogingival junction through the vestibular area, called apical-coronal [5], or the third technique includes one or two vertical incisions with a large lateral load bevel on either side of the defect [7]. Next, the connective tissue graft is taken; the ideal donor sites are the tuberosity of the maxilla, an edentulous area or the palate. There are several techniques for obtaining the graft, Langer and Langer, in 1985 described the technique based on the realization of three incisions, two vertical and one horizontal; Bruno in 1994, described another technique that consisted of the realization of two horizontal linear incisions [8]. Finally, Hurzeler described in 1999, a technique in which he makes a single linear incision where grafts of varying size and thickness can be obtained [9] [10]. In the superimposed or onlay procedures, the recipient bed is prepared by de-epithelializing the epithelial tissue, and superimposing a graft free of epithelial tissue to gain height of the alveolar ridge; this type of grafts would be indicated in Seibert class III [11].

The selection of the most suitable ceramic system without metal for a patient, which matches the intraoral conditions and aesthetic requirements, is a highly demanding and challenging procedure [12]. Translucent Zirconia has important 
aesthetic properties, and allows the adoption of certain characterizations and therefore is used in both anterior and posterior areas; many articles on monolithic Zirconia have been reported in natural teeth and implants [13].

The objective of this case report was to demonstrate how the technique of tissue modification in an area with a class b defect of Allen allows the correction of aesthetics by using Zirconia crowns in the anterior sector.

\section{Case Report}

A Female patient of 41 years of age, without pathological, personal, family, surgical or allergic background, not currently a smoker without any pharmacological treatment. Reason for consultation "I do not like how my prosthesis looks". Patient reports having suffered a car accident about 30 years ago losing his left upper central incisor and since then she wears a fixed porcelain metal prosthesis. The informed consent was signed by the patient. After assessment of the clinical history, plaque index, bleeding index and periodontogram were performed, presenting periodontal pockets greater than $4 \mathrm{~mm}$ at the level of the lower third molars, which are indicated for exodontia due to recurrent episodes of periocoronitis. Initial intraoral photograph (Figure 1(a)). Fixed porcelain fused to metal

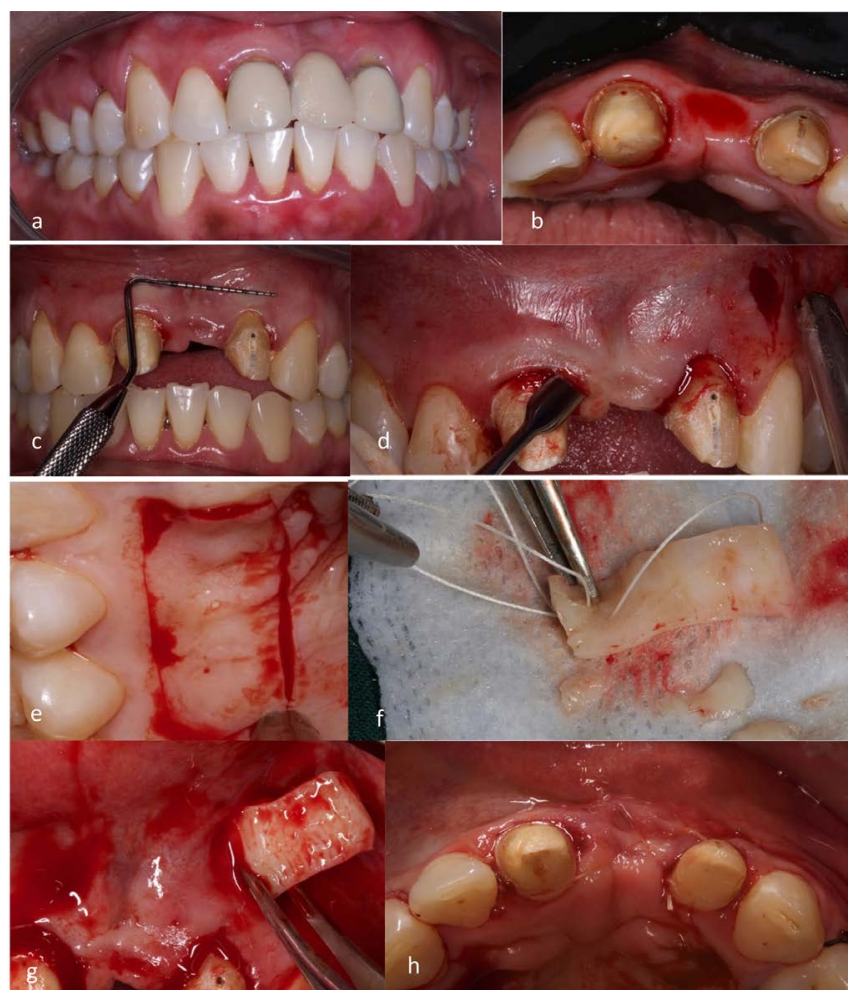

Figure 1. (a) Initial situation; (b) Occlusal view of the Allens class b; (c) Measuring with periodontal probe; (d) Full thickness flap lifting; (e) Horizontal and vertical incisions for palatal graft; (f) Connective tissue is sutured to help introduce it into the receiving area; (g) Graft introduction; (h) The graft is firmly sutured to the tissue avoiding its displacement towards the bottom of the vestibule. 
poorly adjusted prosthesis from teeth \#11 to \#22, Miller class I gingival recession in tooth \#13 was observed, which was covered in the first surgical act by the Langer and Langer technique [14]. Removal of porcelain fused to metal prosthesis, upper occlusal photographs showing the class B defect of Allen (Figure $1(\mathrm{~b})$ ). Asepsis and antisepsis with $0.12 \%$ chlorhexidine, $2 \%$ lidocaine infiltrate local anesthesia at the vestibule and palatal level of the upper anterior area and upper left premolar area for graft. Measurement of the mesiodistal defect of approximately $12 \mathrm{~mm}$ with the North Carolina periodontal probe was performed to reference the size of the graft necessary to be taken in the palatal area (Figure $1(c)$ ). A vertical incision is made with a scalpel blade $15 \mathrm{c}$ mesial OD 23 mucogingival junction to coronal without invading gingival margin and crevicular incision of teeth \#11 and \#22. Full thickness flap with periosteotome P20 in the length of the defect (Figure 1(d)). Two horizontal and two vertical incisions are made at the right upper premolar level (Figure 1(e)), and we proceeded with the removal of the connective tissue and epithelium. On a sterile gauze with physiological saline, the graft is de-epithelialized and fixed with resorbable suture (Figure 1(f)). We introduce the graft approximately $21 \times 6 \times 3 \mathrm{~mm}$ and it is pulled to the desired position (Figure $1(\mathrm{~g})$ ). The suture is terminated by finding support in adjacent teeth (Figure $1(\mathrm{~h})$ ). Postoperative six weeks of evolution (Figure 2(a)), prior to the second surgical act to cover gingival recession and increase in volume, using the Langer and Calagna technique [8]. Asepsis and antisepsis, infiltrate local anesthesia at the vestibule and palatal levels of upper anterior, and upper left premolar area for graft. In the Langer and Calagna technique,

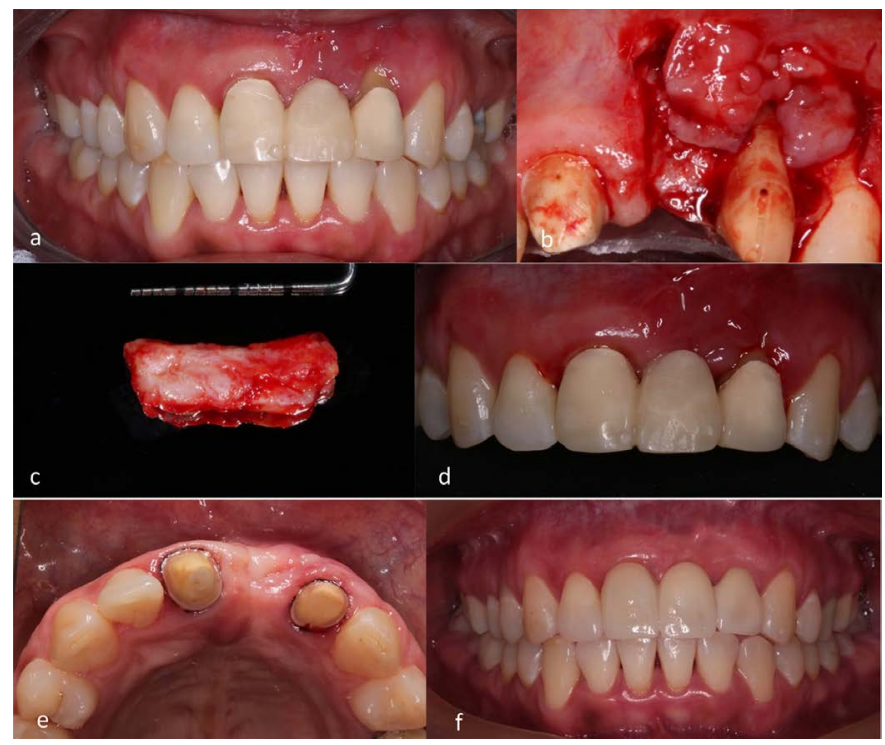

Figure 2. (a) Gingival recession is evident at the level of tooth \#21 and very little keratinized gingival; (b) Preparation of receiving area; (c) Connective tissue extracted from the palate; (d) Postoperative 02 weeks of evolution; (e) Occlusal photograph showing significant volume increase; (f) Cementation of fixed zirconia prosthesis, final result. 
in most cases, the horizontal incision is made on the edentulous alveolar ridge that connects two vertical incisions, which will facilitate the elevation and malleability of the flap and the subsequent coverage of the donor graft. The connective tissue is left covering the alveolar bone, this will provide a double source of vascular supply for the donor connective tissue that is from the lower part of the epithelium and the connective tissue in the alveolar bone [6] (Figure 2(b)). The connective tissue graft is taken from the palate with the Langer and Langer [15] technique of approximately $16 \times 6 \times 3 \mathrm{~mm}$ (Figure $2(\mathrm{c})$ ). The connective tissue graft is sutured to the connective tissue that covers the alveolar bone and to the buccal flap superimposed with a resorbable suture. The use of periodontal dressing in the recipient site is optional as well as in the donor site. Postoperative 15 days of evolution (Figure 2(d)). Final result at eight weeks of evolution prior to the final impression of a fixed restoration with Zirconia, there is evidence of volume increase (Figure 2(e)).

The zirconia, according to the manufacturer's instructions, can be by conventional cementation. In this case, we use low viscosity composite resin cement (RelyX ${ }^{\oplus}$ U $2003 \mathrm{M}$ ) for both abutment crowns [16] (Figure 2(f)). It should be mentioned that in addition to the fixed rehabilitation with zirconia, endodontic treatments were also performed on tooth \#25 due to asymptomatic apical periodontitis, rehabilitation with lithium disilicate crown on tooth \#25 and incrustations of lithium disilicate on teeth \#17,36,46, direct rehabilitations with composite in cervical of tooth \#15, occlusal of teeth \#15,16,24,26,27,35,37,44, 45 and 47 and incisal edges of 31, 32, 41 and 42 . The prognosis of our patient after the treatment was favorable, and she was followed up at 12 months and 24 months post-treatment without presenting any complications.

\section{Discussion}

Before reconstructing the collapse of the alveolar ridge, we must take into account a series of factors, such as the morphology of the defect [9]. This case report is similar to others where the importance of the quantity and quality of soft tissue existing in the edentulous area to allow the elevation of a flap and, therefore, avoid perforation of It, thus achieving the increase in volume necessary for the placement of dental crowns [17].

One of the techniques that was used for the connective tissue graft was the one described by Langer and Langer since this technique achieves the necessary volume of graft suitable for our receptor site, in addition to leaving the epithelium in the donor site. Good results are achieved during the postoperative period. Other authors suggest that anatomical knowledge is necessary when choosing the donor area as the palate. In this treatment, the volume of tissue necessary for dental rehabilitation was obtained through the use of Zirconia crowns similar to others reports [10]. The tunnel technique and the technique of Langer and Calagna gave us a series of advantages, such as the gain of an ideal volume without intraoperative or postoperative complications, the covering of the gingival reces- 
sions and a good adaptation of the color of the gingiva, a very important factor due to the aesthetic demand of the anterior area, in this case report no postoperative complications were presented [8].

The modified saddle type pontic, designed in our case, resulted in excellent aesthetics in the receiving area, achieving good hygiene control by the patient, which is similar to that reported by Garber and Rosenberg. They mentioned that the contact of the pontic with the underlying soft tissue is maintained only in the vestibular aspect of the ridge, this limited contact in a single plane allows the area to be easily cleaned with dental floss and kept free of inflammation [2]. In our case report, restorations of fixed prostheses from the anterior sector with zirconia were made, as it is indicated for multiple unit and individual restorations, similar to that reported by Studart et al. where they suggest that zirconia can resist loads typically applied in the molar region, and even more in the anterior sector providing a flexural strength greater than $900 \mathrm{MPa}$ [18]. The masticatory forces being $250 \mathrm{~N}$ and up to $800 \mathrm{MPa}$ during movements of the stomatognathic apparatus.

We limit the lithium disilicate only to individual posterior restorations since their mechanical properties are recommended for anterior and posterior individual crowns and a short three units anterior fixed dental prostheses [19]. However, more studies are needed to investigate the differences that exist between the different restorative systems.

\section{Conclusion}

Through the increase of the ridge with a connective tissue tunnel graft and a modification of the gingival margin through pontics, very good aesthetic and functional results are achieved, facilitating the hygiene of the area. Surgery of residual alveolar ridge augmentation with connective tissue graft gives the patient favorable results and is low cost since no additional filling materials are needed. The success rate of fixed prostheses with zirconia structures, demonstrated by studies of medium-term clinical follow-up, is very high.

\section{Acknowledgements}

This investigation was supported by CONACYT CB-2014-01 [grant No. 242939], CONACYTINFR-2014-01 [grant No. 226467].

\section{References}

[1] Gray, J.L. and Quattlebaum, J.B. (1988) Correction of Localized Alveolar Ridge Defects Utilizing Hydroxyapatite and a "Tunneling" Approach: A Case Report. International Journal of Periodontics \& Restorative Dentistry, 8, 72-8.

[2] Garber, D.A. and Rosenberg, E.S. (1981) The Edentulous Ridge in Fixed Prosthodontics. The Compendium on Continuing Education in General Dentistry, 2, 212-23.

[3] Seibert, J.S. and Salama, H. (1996) Alveolar Ridge Preservation and Reconstruction. Periodontology 2000, 11, 69-84. https://doi.org/10.1111/j.1600-0757.1996.tb00185.x 
[4] Liu, C. (2004) Use of a Modified Ovate Pontic in Areas of Ridge Defects: A Report of Two Cases. Journal of Esthetic and Restorative Dentistry, 16, 273-281. https://doi.org/10.1111/j.1708-8240.2004.tb00052.x

[5] Allen, E.P., Gainza, C.S., Farthing, G.G. and Newbold, D.A. (1985) Improved Technique for Localized Ridge Augmentation. A Report of 21 Cases. Journal of Periodontology, 56, 195-199. https://doi.org/10.1902/jop.1985.56.4.195

[6] Langer, B. and Calagna, L. (1980) The Subepithelial Connective Tissue Graft. Journal of Prosthetic Dentistry, 44, 363-367.

https://doi.org/10.1016/0022-3913(80)90090-6

[7] Miller Jr., P.D. (1986) Ridge Augmentation under Existing Fixed Prosthesis. Simplified Technique. Journal of Periodontology, 57, 742-745. https://doi.org/10.1902/jop.1986.57.12.742

[8] Meltzer, J.A. (1979) Edentulous Area Tissue Graft Correction of an Esthetic Defect. A Case Report. Journal of Periodontology, 50, 320-322. https://doi.org/10.1902/jop.1979.50.6.320

[9] Seibert, J.S. (1983) Reconstruction of Deformed, Partially Edentulous Ridges, Using Full Thickness Onlay Grafts. Part I. Technique and Wound Healing. The Compendium on Continuing Education in General Dentistry, 4, 437-453.

[10] Reiser, G.M., Bruno, J.F., Mahan, P.E. and Larkin, L.H. (1996) The Subepithelial Connective Tissue Graft Palatal Donor Site: Anatomic Considerations for Surgeons. The International Journal of Periodontics \& Restorative Dentistry, 16, 130-137.

[11] Hürzeler, M.B. and Weng, D. (1999) A Single-Incision Technique to Harvest Subepithelial Connective Tissue Grafts from the Palate. The International Journal of Periodontics \& Restorative Dentistry, 19, 279-287.

[12] Chekhani, U.N., Mikeli, A.A. and Huettig, F.K. (2013) All-Ceramic Prosthetic Rehabilitation of a Worn Dentition: Use of a Distal Cantilever. Two-Year Follow-Up. Dental Research Journal, 10, 126-131.

[13] De Angelis, F., Brauner, E., Pignatiello, G., Mencio, F., Rosella, D., Papi, P., Di Carlo, T., Giovannetti, A., Pompa, G. and Di Carlo, S. (2017) Monolithic Zirconia and Digital Impression: Case Report. Clinical Therapeutics, 168, e229-e232.

[14] Miller Jr., P.D. (1985) A Classification of Marginal Tissue Recession. The International Journal of Periodontics \& Restorative Dentistry, 5, 8-13.

[15] Langer, B. and Langer, L. (1985) Subepitelial Connective Tissue Graft Technique for Root Coverage. Journal of Periodontology, 56, 715-720.

https://doi.org/10.1902/jop.1985.56.12.715

[16] Tinschert, J., Natt, G., Mautsch, W., Augthun, M. and Spiekermann, H. (2001) Fracture Resistance of Lithium Disilicate-, Alumina-, and Zirconia-Based Three-Unit Fixed Partial Dentures: A Laboratory Study. The International Journal of Prosthodontics, 14, 231-238.

[17] Abrams, L. (1980) Augmentation of the Deformed Residual Edentulous Ridge for Fixed Prosthesis. The Compendium on Continuing Education in General Dentistry, 1, 205-213.

[18] Studart, A.R., Filser, F., Kocher, P. and Gauckler, L.J. (2007) Fatigue of Zirconia Under Cyclic Loading in Water and Its Implications for the Design of Dental Bridges. Dental Materials, 23, 106-114. https://doi.org/10.1016/j.dental.2005.12.008

[19] Marques, J., Montserrat-Bosch, M., Figueiredo, R., Vilchez-Pérez, M.A., Valmaseda-Castellón, E. and Gay-Escoda, C. (2017) Impacted Lower Third Molars and Distal Caries in the Mandibular Second Molar. Is Prophylactic Removal of Lower Third Molars Justified? Journal of Clinical and Experimental Dentistry, 9, e794-e798. 